\title{
Necessary But Not Sufficient: Why Health Care Alone Cannot Improve Population Health and Reduce Health Inequities
}

\author{
Steven H. Woolf, MD, MPH \\ Department of Family Medicine and Population Health and Center on Society and Health, Virginia Commonwealth University, \\ Richmond, Virgina
}

Ann Fam Med 2019;17:196-199. https://doi.org/10.1370/afm.2395.

$\mathrm{T}$ The health of Americans is in decline, a crisis that has been building for some years. Since the 1980s, US life expectancy has risen at a slower pace than in other countries. United States life expectancy peaked in 2012 and is now falling, while life expectancy in other countries continues to increase. ${ }^{1,2}$ Shorter lifespans are not the only US health disadvantage. For many years, other industrialized countries have been outperforming the United States on a long list of health conditions. ${ }^{3}$ All this despite lavish US spending on health care, which far exceeds that of any other country. ${ }^{4}$

The reason why nations that spend less on health care can experience better health is obvious: health is about more than health care. Studies suggest that medical care accounts for only $10 \%$ to $20 \%$ of variation in premature mortality. ${ }^{5}$ In this issue of the Annals, Kaplan and Milstein put a finer point on that estimate. Based on 4 prior studies, they conclude that health care accounts for $5 \%$ to $15 \%$ of the variation in premature mortality, centered on $10 \% .{ }^{6}$ Other studies have examined this issue $^{7-9}$ and researchers will continue to refine this point estimate, but more data are unlikely to change the bottom line: the major influences on health lie outside the clinic. The decline in US health will not be solved by more bench science, more drugs, or more spending on health care-none of these have slowed the decline in US health. The average lifespan of Americans will probably continue to shorten unless society quickly shifts its focus from health care to root causes.

Conflicts of interest: author reports none.

\section{CORRESPONDING AUTHOR}

Steven H. Woolf, MD, MPH

P.O. Box 980101

Virginia Commonwealth University

Fairfax, VA 22033

steven.woolf@vcuhealth.org

\section{WHAT SHAPES HEALTH?}

Health is shaped by 5 domains-(1) health care, (2) health behaviors, (3) the physical and social environment, (4) socioeconomic status, and (5) public policy-all of which have complex interrelationships. ${ }^{5}$ For example, risky behaviors (eg, unhealthy diet, physical inactivity) precipitate chronic diseases but are themselves shaped by the environment. People can only make the choices they have: they cannot eat well if they live in a food desert, they cannot exercise or play outside if the built environment is unsafe. The social environment-eg, domestic trauma, social isolation, residential segregation, structural racism-can also harm health.

Socioeconomic status may be the greatest influence on health. ${ }^{5}$ In a knowledge economy like the United States, education - and the income and wealth it provides-opens the doors to opportunity and health, enabling people to afford medical care, nutritious foods, and homes in healthy neighborhoods. The fifth domain, public policy, influences all of these domains: national, state, and local leaders in public and private sectors influence access to good schools, jobs, and economic opportunity. Policy choices also shape social divides; they either correct or perpetuate inequities among marginalized populations (eg, people of color, immigrants) and neglected neighborhoods.

The complex interlinkages between these 5 domains make it challenging, if not misleading, to quantify how much each domain matters. For example, Hood et al estimated that the relative contributions of socioeconomic factors, health behaviors, clinical care, and the physical environment were $47 \%, 34 \%, 16 \%$, and $3 \%$, respectively. ${ }^{9}$ These domains, however, are not independent: health behaviors and clinical care are determined by socioeconomic and environmental factors, and socioeconomic factors determine one's environment. Putting a number on each domain can help set priorities, but meaningful health improvements are 
difficult to achieve without addressing them all. These interrelationships have important implications for public policy outside of health care, as well as for health care systems and individual clinicians.

\section{PUBLIC POLICY}

Investments in "non-health" sectors like education and housing may do more to save lives than what physicians do at the bedside. ${ }^{5}$ Solving historic health inequities among low-income patients, marginalized racial and ethnic groups, and disadvantaged urban and rural communities requires policies directed at reversing years of disinvestment and spurring economic growth.

No sector alone can do this because the sectors are interconnected: people cannot access jobs or health care, for example, without stable housing, transportation, and child care. Stakeholders across sectors have a shared incentive to address root causes. Teachers, police officers, physicians, and social workers identify the same issues, such as poverty or segregation, which drive not only health inequities but also poor grades, unemployment, crime, and other social ills.

The public health community is hardly the first to recognize the importance of place in shaping inequities. Improving neighborhoods has long been the work of community development organizations. Civic leaders are also motivated to enhance neighborhoods; they know that healthier and safer communities attract new businesses and stimulate economic growth. Employers want healthier communities for their workers. Real estate developers, financial institutions, and investors have incentives to build affordable housing and revitalize low-income neighborhoods. In many communities, these shared incentives are bringing stakeholders together across sectors in collective impact initiatives, seeking to achieve changes together that no sector could accomplish alone..$^{10}$ The return on investment from such efforts cuts across sectors: improved living conditions prevent disease (and related costs) but can also enhance workforce productivity, boost tax revenue, and lower demands for social services, law enforcement, incarceration, and other costly services.

These exciting, but largely local, case studies remain the exception to the rule. As a nation, the United States spends less on social programs than on health care. In comparisons across peer countries ${ }^{11}$ and US states, ${ }_{1}^{12}$ Bradley et al have shown that the ratio of social to medical spending correlates with health outcomes. Given the political climate in Washington, $\mathrm{DC}$ and many states, leadership in reversing this ratio is likely to occur at the local level. Local progress is inspiring but may not be enough to move the needle for the nation. Population health in the United States is likely to languish in the absence of national leadership, and premature deaths may continue to increase.

\section{HEALTH CARE SYSTEMS}

Health care systems cannot solve society's problems, but they can do their part. In the face of payment reforms and increasing accountability for population health outcomes, health care systems are paying greater attention to the social needs of their patients. Addressing unstable housing, for example, has been associated with fewer emergency department visits and hospital admissions. ${ }^{13,14}$ Public (eg, Medicaid) and private health plans are expanding reimbursement for such services. ${ }^{15}$ Health systems' involvement in addressing social needs is occurring at 3 levels of engagement:

\section{Level 1: Assessing Social Needs}

Level 1 health systems may lack formal programs to address social needs but have taken preliminary steps, such as systematically collecting data on the race or socioeconomic conditions of their patients. Such screening can be useful to health systems to better understand their patient population and identify at-risk populations or "hot spot" neighborhoods, and data on living conditions can help inform clinicians' care decisions (see below).

\section{Level 2: Helping Connect Patients With Assistance}

Level 2 health systems have procedures in place to help clinicians connect patients with community resources (eg, housing, transportation, job training). Some refer patients to outside social service agencies or community programs that can direct patients to needed resources. Some health systems staff clinics, emergency departments, and hospitals with social workers or case managers who connect patients with community programs. Some hospitals operate in-house services, such as food pantries. The Centers for Medicare and Medicaid Services is funding 31 Accountable Health Communities in a national experiment to test whether health systems that systematically identify and address social needs can reduce costs and utilization among Medicare and Medicaid beneficiaries. ${ }^{16}$

\section{Level 3: Supporting Community Initiatives to Improve Social Conditions}

Level 3 systems go beyond serving their own patients to join community partners in collective impact initiatives (see above). They are at the table with government leaders, businesses, and other sectors to pursue community-identified goals_often with other health systems or provider groups by their side. Their role 
is to contribute clinical expertise, data, and research capacity (especially at academic health centers). Some health systems have made capital investments in community building programs, such as the construction of mixed-income housing. ${ }^{10}$ Health systems are often among the largest employers in a community and can serve as "anchor" institutions, stimulating economic growth by turning to local businesses for construction, catering, laundry, or other contracts. ${ }^{17}$

Impediments to such efforts are considerable, including the costs (to hospitals and to underfunded safety net agencies with heavy caseloads) and the fragmentation that typically divides health care, social services, and community organizations. Many health systems are inexperienced with community engagement and have not cultivated relationships with local government, the business community, service providers, or residents. ${ }^{18}$

Furthermore, while the budgets that large health care systems can devote to this issue often dwarf those of social service agencies, there is growing concern that a "medicalized" approach to addressing social needs could be costly and ineffective. Evidence that such interventions improve health outcomes is mixed, ${ }_{1}^{19}$ perhaps because the medical model focuses on treating symptoms (the social needs of individual patients) and not the upstream causes (population-based challenges). ${ }^{20,21}$ As explained by the organizers of the 2017 Medicalization of Poverty Symposium, "We spend inordinate amounts of money and other resources to address healthcare needs brought on by poverty instead of providing for the tangible needs of the poor before illness strikes."22

\section{INDIVIDUAL CLINICIANS}

Where does this leave busy clinicians? Although they accept the principle that living conditions are important to health outcomes, clinicians' capacity to address social needs is limited: they were not trained to take on this role, and most lack the time and reimbursement to do so. Although practices can hire personnel and use referral software to make it easier to direct patients to community resources, most have all they can do to deliver basic clinical care and survive economically in today's turbulent health care marketplace. What, then, can clinicians realistically accomplish in addressing the social needs of their patients? Three options are clear, the first being the most important:

\section{Patient Care}

Good medical care requires attention to the socioeconomic status of patients and knowing whether they live in marginalized neighborhoods, assessed either in the routine history or by administering screening instru- ments. This information can help clinicians weigh the patient's risk for disease and design care plans that are realistic to implement. For example, clinicians who know that a patient cannot read English or cannot afford out-of-pocket costs might locate a translator or suggest less expensive medications, respectively. Clinicians who might otherwise not consider the neighborhood environment of their patients can benefit from mapping tools that geocode home addresses and flag "hot spots" with poor living conditions and health outcomes.

\section{Local Advocacy}

Physicians and nurses, whom society holds in high regard, can be a powerful voice in their communities to promote policies that address social needs. Appearing on television or before city councils, physicians are uniquely positioned to argue that such policies can save lives-be they investments in education, affordable housing, livable wages, or public transit. And they can demonstrate by example, such as making choices about where to live or the schools their children will attend, thereby learning firsthand the conditions their patients face.

\section{Organized Medicine}

The collective voice of health care professionals can also shift national, state, and local policy, as when the American Medical Association, American Academy of Family Physicians, or other professional societies take visible positions on salient social issues. Clinicians with a passion for social action can join a variety of organizations that have formal initiatives to address the social determinants of health.

\section{CONCLUSION}

The complex ecosystem that shapes the health of a community explains why health care accounts for only $5 \%$ to $15 \%$ of premature mortality, but such evidence should not be used to diminish the importance of health care. Universal health care insurance coverage, access to primary care, and innovations to improve quality remain vital. Everyone relies on clinicians for the prevention, diagnosis, and treatment of illness and injury. Health care is necessary but not sufficient to improve population health or correct health inequities. Spending lavishly on health care will not solve the US health disadvantage. It began in the 1980s and will continue unabated until that lesson is learned.

To read or post commentaries in response to this article, see it online at http://www.AnnFamMed.org/content/17/3/196.

Key words: social determinants of health; health equity; population health 
Submitted March 25, 2019; accepted March 27, 2019.

Acknowledgments: The author thanks Heidi Schoomaker, MAEd for her helpful comments on this manuscript.

\section{References}

1. National Center for Health Statistics. Health, United States, 2017: With Special Feature on Mortality. Hyattsville, MD: National Center for Health Statistics; 2018.

2. Murphy SL, Xu JQ, Kochanek KD, Arias E. Mortality in the United States, 2017. NCHS Data Brief, no 328. Hyattsville, MD: National Center for Health Statistics; 2018.

3. Woolf SH, Aron L, eds. U.S. Health in International Perspective: Shorter Lives, Poorer Health. Panel on Understanding Cross-National Health Differences Among High-Income Countries. Washington, DC: The National Academies Press; 2013.

4. Papanicolas I, Woskie LR, Jha AK. Health care spending in the United States and other high-income countries. JAMA. 2018;319(10): 1024-1039.

5. Woolf $\mathrm{SH}$. Progress in achieving health equity requires attention to root causes. Health Aff (Millwood). 2017;36(6):984-991.

6. Kaplan RM, Milstein A. Contributions of health care to longevity: a review of 4 estimation methods. Ann Fam Med. 2019;17(3):267-272.

7. Mokdad AH, Marks JS, Stroup DF, Gerberding JL. Actual causes of death in the United States, 2000. JAMA. 2004;291(10):1238-1245.

8. Institute of Medicine and National Research Council. Measuring the Risks and Causes of Premature Death: Summary of Workshops. Washington, DC: The National Academies Press; 2015.

9. Hood CM, Gennuso KP, Swain GR, Catlin BB. County Health Rankings: relationships between determinant factors and health outcomes. Am J Prev Med. 2016;50(2):129-135.

10. Dailey C, Elias RR, Moore A. Summarizing the Landscape of Healthy Communities: An Environmental Scan of Demonstration Programs Working Towards Health Equity. San Francisco, CA: Build Healthy Places Network; 2016.

11. Bradley EH, Elkins BR, Herrin J, Elbel B. Health and social services expenditures: associations with health outcomes. BMJ Qual Saf. 2011;20(10):826-831.
12. Bradley EH, Canavan M, Rogan E, et al. Variation in health outcomes: the role of spending on social services, public health, and health care, 2000-09. Health Aff (Millwood). 2016;35(5):760-768.

13. Moore DT, Rosenheck RA. Comprehensive services delivery and emergency department use among chronically homeless adults. Psychol Serv. 2017;14(2):184-192.

14. Health Research $\&$ Educational Trust. Housing and the Role of Hospitals. Chicago, IL: Health Research \& Educational Trust; 2017.

15. Paradise J, Ross DC. Linking Medicaid and Supportive Housing: Opportunities and On-the-Ground Examples. Menlo Park, CA: Kaiser Family Foundation; 2017.

16. Centers for Medicare and Medicaid Services. Accountable health communities model. https://innovation.cms.gov/initiatives/ahcm/. Accessed Feb 18, 2019.

17. Harkavy I. Engaging urban universities as anchor institutions for health equity. Am J Public Health. 2016;106(12):2155-2157.

18. Woolf SH, Zimmerman E, Haley A, Krist AH. Authentic engagement of patients and communities can transform research, practice, and policy. Health Aff (Millwood). 2016;35(4):590-594.

19. Gottlieb LM, Wing $H$, Adler NE. A systematic review of interventions on patients' social and economic needs. Am J Prev Med. 2017; 53(5):719-729.

20. Lantz PM. The medicalization of population health: who will stay upstream? Milbank Q. 2019;97(1):36-39.

21. Castrucci B, Auerbach J. Meeting individual social needs falls short of addressing social determinants of health. Health Affairs blog. https://www.healthaffairs.org/do/10.1377/hblog20190115.234942/ full/. Published Jan 16, 2019. Accessed Feb 18, 2019.

22. Carle health system, the Epstein Health Law and Policy Program at the University of Illinois College of Law, the University of Virginia Department of Public Health Sciences, the University of Virginia School of Medicine Center for Biomedical Ethics and Humanities, the Carl R. Woese Institute for Genomic Biology at the University of Illinois at Urbana-Champaign, et al. The Medicalization of Poverty Symposium. https://globalhealth.illinois.edu/2017/10/02/ the-medicalization-of-poverty-symposium/. 